\title{
Descrição botânica de linhagens puras selecionadas de guandu
}

\author{
Milena Provazi ${ }^{1}$, Lívia Haik Guedes de Camargo', Patricia Menezes Santos², Rodolfo Godoy² \\ 1 Estagiária da Embrapa Pecuária Sudeste. \\ 2 Embrapa Pecuária Sudeste - CP 339 - CEP: 13500-970 - São Carlos, SP.
}

RESUMO - Este estudo foi desenvolvido com o objetivo de realizar a descrição botânica de 11 linhagens de Cajanus cajan. Os principais descritores foram: hábito de crescimento, altura de plantas ( $\mathrm{cm}$ ), número de ramos, diâmetro do caule $(\mathrm{mm})$, cor básica da flor, cor básica da vagem, cor das sementes, cor em volta do hilo das sementes, largura do hilo e forma das sementes. Os descritores utilizados mostraram-se suficientes para caracterizar as linhagens com características distintas, pelas quais podem ser facilmente identificadas.

Palavras-chave: avaliação de forrageira, Cajanus cajan, descrição botânica, leguminosa forrageira tropical

\section{Botanical description of selected pigeon-pea pure lines}

\begin{abstract}
This work aimed to perform the morphologic characterization of eleven previously selected Cajanus cajan lines. The main descriptors were: plant height $(\mathrm{cm})$, number of branches, stem diameter $(\mathrm{mm})$, basic flower color, basic pod color, seed color, seed hilum color, hilum thickness, and seed shape. The descriptors used were sufficient to characterize the lines with distinct characteristics. Using these descriptors the lines may be easily identified.
\end{abstract}

Key Words: botanical description, Cajanus cajan, forage evaluation, tropical forage legume

\section{Introdução}

O guandu (Cajanus cajan(L.) Millsp)éuma leguminosa com seu centro de origem e de diversidade genética na Índia. Consiste em importante fonte de proteína em muitos países da África e da Ásia, sendo freqüentemente citado como uma espécie de múltiplo uso e por sua tolerância a condições adversas, como o estresse hídrico causado por longos períodos de estiagem e por solos de baixa fertilidade, condições encontradas no Cerrado brasileiro. Como grande parte dos sistemas de produção de carne e de leite do Brasil está instalada em áreas de cerrado, uma das principais estratégias para o aumento da eficiência produtiva desses sistemas é a utilização de plantas forrageiras adaptadas a essas condições.

O guandu vem sendo utilizado na alimentação animal, tanto em pastagens exclusivas e consorciadas como em forma de forragem verde, feno e componente de mistura de silagem (Werner, 1979; Wutke, 1987). Vários estudos caracterizando genótipos de guandu evidenciaram a extraordinária variabilidade genética desta espécie (Werner, 1979; Wutke, 1987; Colombo, 1989). Considerando as limitações de qualidade e o reduzido número de cultivares comerciais, Godoy et al. (1994) e Godoy et al. (1997) avaliaram agrono- micamente duas coleções de germoplasma de guandu e verificaram que todos os acessos selecionados apresentavam, em graus variáveis, misturas físicas e/ou segregação fenotípica. Assim, os acessos selecionados por características forrageiras favoráveis passaram por processos de autofecundação e seleção para obtenção de linhagens puras. A partir de 1998, Godoy et al. (2003) reavaliaram agronomicamente 17 dessas linhagens para confirmação de seus respectivos desempenhos agronômicos, caracterizando-as morfologicamente e descrevendo seu ciclo vegetativo. Posteriormente, Godoy et al. (2004) caracterizaram e descreveram mais 11 daquelas linhagens puras.

A descrição permitirá a agilização da solicitação de registro e proteção junto ao Ministério da Agricultura, Pecuária e Abastecimento quando forem lançados novos cultivares e ainda servirá para a correta identificação desses acessos no campo. O lançamento de novos cultivares contribuirá para solucionar problemas relacionados a sistemas de produção sustentável de carne e de leite, reduzindo os custos e a sazonalidade, melhorando a alimentação animal e aumentando a produção animal.

Este trabalho foi realizado com os objetivos de descrever botanicamente 11 linhagens puras selecionadas de guandu e verificar a eficiência dos descritores utilizados. 


\section{Material e Métodos}

As caracterizações morfológicas das linhagens puras foram feitas em um bloco de experimento de avaliação agronômica instalado na Embrapa Pecuária Sudeste, no município de São Carlos (SP), localizado a $21^{\circ} 57^{\prime} 42^{\prime \prime}$ de latitude sul, $47^{\circ} 50^{\prime} 28^{\prime \prime}$ de longitude oeste e a $860 \mathrm{~m}$ de altitude.

O experimento foi implantado em 23 de dezembro de 2004, com 11 tratamentos (linhagens puras de Cajanus cajan) e três repetições. As parcelas foram constituídas de cinco linhas de $5 \mathrm{~m}$ de comprimento, com $0,5 \mathrm{~m}$ de espaçamento entre linhas e $0,25 \mathrm{~m}$ entre plantas, totalizando 20 plantas na linha.

Os descritores utilizados, adaptados do International Board for Plant Genetic Resources (IBPGR, 1993) e International Crop Research Institute for the Semi-Arid Tropics (ICRISAT, 1993), foram: hábito de crescimento; altura de plantas (cm) - 50\% das plantas encontravam-se em florescimento); número de ramos primários; número de ramos secundários; cor do caule; diâmetro do caule $(\mathrm{mm})$ a $40 \mathrm{~cm}$ de altura (50\% das plantas em florescimento [todos esses dados avaliados pela média de cinco plantas]); forma do folíolo; pilosidade do folíolo; cor básica (cor principal das pétalas) e cor secundária da flor; padrão das estrias da flor; padrão de florescimento; cor da vagem verde; forma e pilosidade da vagem; cor da vagem madura; padrão de coloração das sementes; cores básica e secundária das sementes; cor em volta do hilo das sementes; largura do hilo; e forma das sementes. Na descrição das cores, foram obedecidos os padrões da RSH Colour Chart (2001).

Foram considerados de hábito ereto os genótipos cujos ramos primários faziam ângulo menor que $60^{\circ}$ com o caule. Aqueles cujos ângulos estavam entre 60 e $90^{\circ}$ foram classificados como de hábito semiprostado.

O padrão das estrias das flores, o padrão de coloração das sementes e a forma das sementes foram adaptados de IBPGR \& ICRISAT (1993).

\section{Resultados e Discussão}

Os resultados são apresentados nas Tabelas 1 a 4 e, a seguir, são descritas as características observadas nessa coleção. Neste estudo, dos quatro possíveis hábitos de crescimento entre os genótipos de guandu (ereto e compacto, semiprostrado, prostrado e rasteiro) (IBPGR \& ICRISAT, 1993), apenas um foi observado nas linhagens avaliadas, ou seja, o hábito de crescimento ereto, com os ramos primários fazendo ângulo menor que $60^{\circ}$ com o caule. Este resultado difere do obtido por Godoy et al. (2003) e Godoy et al. (2004), que observaram dois hábitos de crescimento (ereto e semiprostrado), todavia, naqueles trabalhos não foi constatada predominância do hábito ereto nos genótipos selecionados.

Entre as quatro linhagens estudadas por IBPGR \& ICRISAT (1993), todas tiveram folíolos lanceolados e pubescentes. Godoy et al. (2003), no entanto, encontraram, além de folíolos lanceolados, folíolos com forma elíptica larga. No trabalho de Godoy et al. (2004), também foram observados folíolos com forma elíptica estreita, além dos tipos anteriormente citados. Em ambos os trabalhos, todos os folíolos eram pubescentes.

Na Tabela 1 são apresentados os dados de altura, número de ramos primários e secundários, cor e diâmetro do caule das linhagens selecionadas.

Seria desejável que as plantas para utilização como forrageira fossem relativamente baixas (aproximadamente $50 \mathrm{~cm}$ de altura) para facilitar o consumo pelos animais e/ou os cortes. Neste caso, a linhagem g59-95 apresentou $67 \mathrm{~cm}$ de altura com $50 \%$ de plantas em florescimento, sendo considerada baixa. Duas linhagens tiveram alturas médias de 70 a $90 \mathrm{~cm}$ (g146-94 e g123-99); duas, de 90 a $110 \mathrm{~cm}$ (g119-99 e g10-94); duas, de 110 e 130 cm (g168-99, g29m-94); e duas, de 130 a $150 \mathrm{~cm}$ (g9m-97 e g1m95). As outras duas linhagens (g48-95 e g121-99) apresentaram, respectivamente, 154 e $172 \mathrm{~cm}$ de altura, sendo consideradas altas.

O número de ramos primários em geral foi superior ao encontrado por Godoy et al. (2003), mas inferior ao registrado por Godoy et al. (2004), pois as linhagens avaliadas neste estudo apresentaram alturas intermediárias àquelas estudadas por esses autores. Apenas uma linhagem apresentou, em média, dez ou menos ramos primários (g59-95); sete linhagens, de 11 a 20 ramos primários (g121-99, g168-99, g9m-97, g1m-95, g29m-94, g146-94 e g123-99); e três, em média, mais que 21 ramos primários (g48-95, g119-99 e g10-94).

O número de ramos secundários é uma característica importante, pois caules com diâmetros menores facilitam o acesso do animal à planta. Em apenas duas linhagens, verificou-se essa característica (g121-99, g48-95, com 12, 29 e 15 ramos secundários, respectivamente). Quatro linhagens apresentaram, em média, de 5 a 10 ramos (g123-99, g29m-94, g1m-95 e g168-99) e cinco tiveram menos que cinco ramos secundários (g10-94, g146-94, g59-95, g119-99 e g9m-97).

Todas as linhagens descritas neste trabalho tiveram caule com estrias dos grupos amarelo-esverdeado 150D (g48-95), branco-acinzentado 156B (g121-99, g168-99, 
Tabela 1 - Altura das plantas, número de ramos, cor e diâmetro do caule de linhagens puras de guandu Table 1 - Plant height, number of branches, stem color and stem diameter of pigeon-pea pure lines

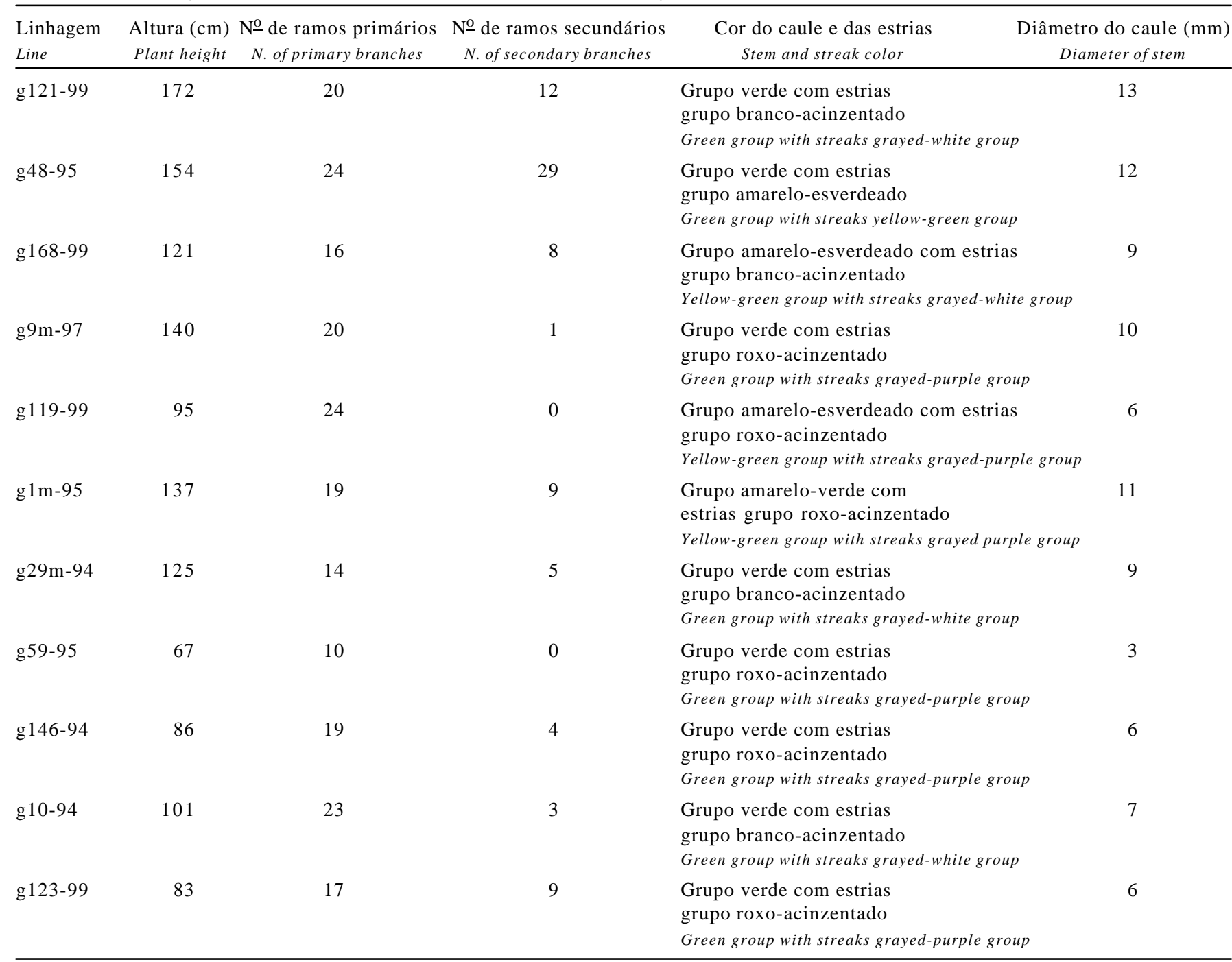

g29m-94, g10-94) e roxo-acinzentado 187D (g9m-97, g119-99, g1m-95, g59-95, g146-94, e g123-99). As cores do caule são dos grupos verde 138A (g123-99), 143A (g48-95 e g9m-97), 143B (g121-99, g29m-94 e g10-94) e 143C (g59-95) e amareloverde 144B (g119-99), 144D (g168-99), 146B (g1m-95).

A maioria dos genótipos apresentou, segundo IBPGR \& ICRISAT, diâmetro de caules (1993) intermediário (5 a 13 mm) (g119-99, g146-94, g123-99, g10-94, g168-99, g29m-94, g9m-97, g1m-95, g48-95 e g121-99) e apenas um genótipo apresentou caule fino (menor que $5 \mathrm{~mm}$ ) (g59-95). Caules finos ou intermediários são mais interessantes em plantas forrageiras, o que possibilita maior consumo e qualidade da forragem. Godoy et al. (2004) encontraram apenas caules de tamanho intermediário nas linhagens selecionadas e, em outro estudo (Godoy et al., 2003), verificaram poucas linhagens com caules grossos.
Em todos os genótipos, observou-se padrão médio de estrias nas flores. Godoy et al. (2003) observaram todos os padrões de estrias descritos em IBPGR \& ICRISAT (1993), sendo que, nas linhagens avaliadas por esses autores, o padrão uniforme foi o mais freqüente. Godoy et al. (2004), no entanto, descreveram linhagens sem estrias e com os padrões médio, esparso, uniforme e denso, sendo o esparso o mais freqüente.

Sete linhagens apresentaram como cor primária da flor (Tabela 2) o grupo amarelo 7A (g29m-94), 12A (g121-99, g9m-97 e g59-95) e 13A (g168-99, g146-94, g10-94 e g123-99) e três tiveram como cor básica da flor o grupo amareloalaranjado 14A (g119-99) e 14B (g48-95 e g1m-95).

Na avaliação da cor secundária da flor, cinco linhagens apresentaram flores com estrias (Tabela 2): g168-99 - cor secundária grupo amarelo $12 \mathrm{~A} \mathrm{com} \mathrm{estrias} \mathrm{do} \mathrm{grupo} \mathrm{verme} \mathrm{lho}$ 
Tabela 2 - Cor das flores de linhagens puras de guandu

Table 2 - Flower color pattern of pigeon-pea pure lines

\begin{tabular}{|c|c|c|}
\hline $\begin{array}{l}\text { Linhagem } \\
\text { Line }\end{array}$ & $\begin{array}{l}\text { Cor primária da flor } \\
\text { Primary flower color }\end{array}$ & $\begin{array}{l}\text { Cor secundária da flor } \\
\text { Secondary flower color }\end{array}$ \\
\hline g 121-99 & $\begin{array}{l}\text { Grupo amarelo } \\
\text { Yellow group }\end{array}$ & $\begin{array}{l}\text { Grupo amarelo } \\
\text { Yellow group }\end{array}$ \\
\hline g48-95 & $\begin{array}{l}\text { Grupo amarelo-alaranjado } \\
\text { Yellow-orange group }\end{array}$ & $\begin{array}{l}\text { Grupo vermelho-arroxeado } \\
\text { Red-purple group }\end{array}$ \\
\hline g168-99 & $\begin{array}{l}\text { Grupo amarelo } \\
\text { Yellow group }\end{array}$ & $\begin{array}{l}\text { Grupo amarelo com estrias grupo vermelho } \\
\text { Yellow group with streaks red group }\end{array}$ \\
\hline g9m-97 & $\begin{array}{l}\text { Grupo amarelo } \\
\text { Yellow group }\end{array}$ & $\begin{array}{l}\text { Grupo amarelo } \\
\text { Yellow group }\end{array}$ \\
\hline g 119-99 & $\begin{array}{l}\text { Grupo amarelo-alaranjado } \\
\text { Yellow-orange group }\end{array}$ & $\begin{array}{l}\text { Grupo amarelo-alaranjado com estrias } \\
\text { grupo vermelho-arroxeado } \\
\text { Yellow-orange group with streaks red purple group }\end{array}$ \\
\hline $\mathrm{g} 1 \mathrm{~m}-95$ & $\begin{array}{l}\text { Grupo amarelo-alaranjado } \\
\text { Yellow-orange group }\end{array}$ & $\begin{array}{l}\text { Grupo vermelho } \\
\text { Red group }\end{array}$ \\
\hline g59-95 & $\begin{array}{l}\text { Grupo amarelo } \\
\text { Yellow group }\end{array}$ & $\begin{array}{l}\text { Grupo amarelo com estrias grupo vermelho } \\
\text { Yellow group with streaks red group }\end{array}$ \\
\hline g146-94 & $\begin{array}{l}\text { Grupo amarelo } \\
\text { Yellow group }\end{array}$ & $\begin{array}{l}\text { Grupo amarelo } \\
\text { Yellow group }\end{array}$ \\
\hline g 10-94 & $\begin{array}{l}\text { Grupo amarelo } \\
\text { Yellow group }\end{array}$ & $\begin{array}{l}\text { Grupo amarelo } \\
\text { Yellow group }\end{array}$ \\
\hline g 123-99 & $\begin{array}{l}\text { Grupo amarelo } \\
\text { Yellow group }\end{array}$ & $\begin{array}{l}\text { Grupo amarelo com estrias grupo vermelho } \\
\text { Yellow group with streaks red group }\end{array}$ \\
\hline
\end{tabular}

46A; g119-99 - cor secundária grupo amarelo-alaranjado 14C com estrias grupo vermelho-arroxeado 60A; g59-95 cor secundária grupo amarelo $12 \mathrm{~A}$ com estrias grupo vermelho 34A; g123-99 - cor secundária grupo amarelo 13C com estrias grupo vermelho 46A. As demais linhagens apresentaram cores secundárias dos grupos amarelo $2 \mathrm{~A}$ (g29m-94), 2B (g121-99), 4B (g9m-97), 8B (g146-94) e 9A (g10-94 e g1m-95) e vermelho-roxo 59C (g48-95).

Seis linhagens tiveram padrão de florescimento determinado; as demais linhagens, padrão indeterminado. A mesma proporção foi encontrada por Godoy et al. (2003).

As vagens de todas as linhagens puras caracterizadas neste estudo tiveram forma achatada e foram pubescentes. Godoy et al. (2003) observaram nos genótipos estudados vagens com formas achatada e cilíndrica, sendo que a forma achatada foi a mais encontrada e todas as vagens eram pubescentes. No entanto, Godoy et al. (2004) encontraram vagens lisas e pubescentes nas formas achatada estreita, achatada larga e cilíndrica.

A classificação da cor da vagem simplesmente como verde ou madura não é suficiente para caracterizar uma linhagem. As vagens verdes das linhagens selecionadas apresentaram cores do grupo amarelo-esverdeado 144A (g121-99, g9m-97, g59-95, g146-94 e g123-99) e 144C (g119-99) e grupo marrom 200A (g168-99). As demais linhagens tiveram vagens verdes com estrias: linhagem g48-95 - vagens com coloração do grupo amarelo-esverdeado 146C com estrias do grupo roxo-acinzentado 187A; g1 m-95 - cor do grupo verde 143B com estrias do grupo roxoacinzentado 187A; e g29m-94 e g10-94 - cor do grupo verde 143C com estrias do grupo verde 143A (Tabela 3). As vagens das linhagens g9m-97 e g1m-95, ao amadurecerem, apresentaram coloração do grupo laranja-acinzentado 161 A com estrias grupo roxo N177A. A linhagem g48-95 apresenta vagens maduras na cor do grupo amarelo-acinzentado $161 \mathrm{~A}$ com estrias do grupo laranja-acinzentado 176A. As vagens maduras do genótipo g119-99 tiveram coloração do grupo laranja-acinzentado 164B com pintas grupo laranjaacinzentado 165B, enquanto as da linhagem g59-95, vagens amadurecidas na cor do grupo cinza-amarronzado 199C. As vagens das linhagens g10-94 e g167-97, ao amadurecer, tiveram coloração do grupo amarelo-acinzentado $161 \mathrm{~A}$ com pintas grupos marrom 200A e marrom 200A, respectivamente. As vagens maduras das cinco linhagens (g121-99, g168-99, g29m-94, g146-94 e g123-99) tiveram cor laranjaacinzentado 164A (Tabela 3).

Como demonstrado na Tabela 4, as linhagens g121-99 e g119-99 tiveram sementes pintadas, enquanto as linha- 
Tabela 3 - Cor das vagens de linhagens puras de guandu

Table 3 - Pod color of pigeon-pea pure lines

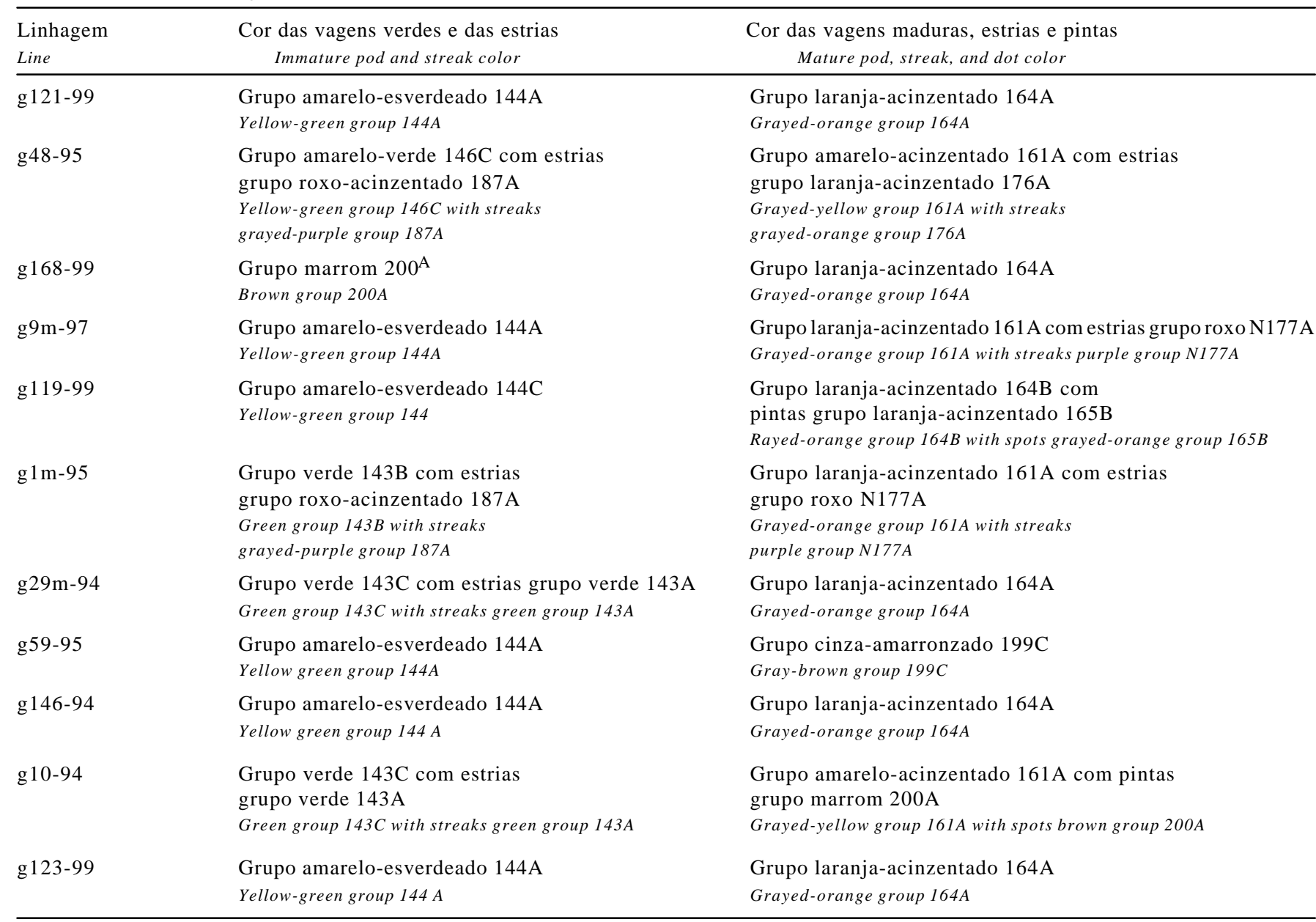

gens g168-99 e g123-99, sementes manchadas e pintadas. As demais linhagens produziram sementes manchadas. Os padrões anular e liso não foram encontrados em nenhuma das linhagens estudadas.

As sementes tiveram como cor básica os grupos laranjaacinzentado 164A (g10-94), 165B (g168-99), 166A (g59-95), 166B (g1m-95), 166D (g29m-94), N167B (g121-99), N167C (g9m-97 e g123-99) e 173C (g48-95), laranjaesbranquiçado 159C (g119-99) e amarelo-esbranquiçado 158C (g146-94) (Tabela 4). Todas as linhagens apresentaram cor secundária nas sementes e coloração do grupo laranjaacinzentado 156A (g146-94), 156C (g119-99), 166A (g1m-95 e g10-94), 166B (g9m-97, g123-99 e g29m-94), 166D (g59-95), N167C (g121-99), 174A (g48-95) e 175A (g168-99) (Tabela 4).

Uma linhagem apresentou largura de hilo de $1 \mathrm{~mm}$ (g5995); três, 1,5 mm (g168-99, g1m-95 e g10-94); e outras seis, 2 mm (g121-99, g48-95, g9m-97, g29m-94, g146-94 e g123-99); e uma, 2,5 mm (g119-99). Os hilos das sementes tiveram cor dos grupos branco 155A (g146-94 e g10-94), 155B (g48-95 e g29m-94), 155C (g121-99 e g123-99) e 155D (g168-99, g9m-97 e g59-95) e amarelo-esbranquiçado 158A (g119-99e g1m-95) (Tabela 4). No grupo de linhagens descrito por Godoy et al. (2003), a maioria das linhagens apresentou hilos com coloração do grupo marrom-avermelhado.

As linhagens g121-99 e g168-99 produziram sementes ovais; as linhagens g119-99, g1m-95, g59-95 e g123-99, sementes redondas; e as linhagens g48-95, g9m-97, g29m-94, g146-94 e g10-94, sementes quadradas. Não foram encontradas sementes alongadas, ao contrário do observado por Godoy et al. (2003), que verificaram sementes alongadas, ovais e quadradas.

Conforme constatado por Godoy et al. (2003) e Godoy et al. (2004), também para este grupo de linhagens, as características morfológicas utilizadas revelaram-se adequadas para sua distinção. Verificou-se ainda que a maior parte das linhagens pode ser individualmente distinguida apenas pelas características de suas sementes.

Godoy et al. (2003) sugeriram que, embora este tipo de trabalho em grandes coleções requeira elevado número de descritores, em coleções menores, é necessário buscar a simplificação dos descritores propostos por IBPGR \& ICRISAT (1993), principalmente quanto à descrição das 
Tabela 4 - Caracterização das sementes de linhagens puras de guandu Table 4 - Seed characteristics of pigeon-pea pure lines

\begin{tabular}{|c|c|c|c|c|c|c|}
\hline $\begin{array}{l}\text { Linhagem } \\
\text { Line }\end{array}$ & $\begin{array}{l}\text { Padrão de } \\
\text { coloração } \\
\text { Color pattern }\end{array}$ & $\begin{array}{l}\text { Cor básica da } \\
\text { semente } \\
\text { Basic seed color }\end{array}$ & $\begin{array}{l}\text { Cor secundária da } \\
\text { semente } \\
\text { Secondary seed color }\end{array}$ & $\begin{array}{l}\text { Cor em volta } \\
\text { do hilo } \\
\text { Color around hilum }\end{array}$ & $\begin{array}{l}\text { gura do } \\
\text { ( } \mathrm{mm}) \\
\text { thickness }\end{array}$ & $\begin{array}{l}\text { Forma da } \\
\text { semente } \\
\text { Seed shape }\end{array}$ \\
\hline g 121-99 & $\begin{array}{l}\text { Pintada } \\
\text { Dotted }\end{array}$ & $\begin{array}{l}\text { Grupo laranja- } \\
\text { acinzentado N167B } \\
\text { Grayed-orange group N167B }\end{array}$ & $\begin{array}{l}\text { Grupo laranja- } \\
\text { acinzentado N167C } \\
\text { Grayed-orange group N167C }\end{array}$ & $\begin{array}{l}\text { Grupo branco } 155 \mathrm{C} \\
\text { White group } 155 \mathrm{C}\end{array}$ & 2 & $\begin{array}{l}\text { Oval } \\
\text { Oval }\end{array}$ \\
\hline g48-95 & $\begin{array}{l}\text { Manchada } \\
\text { Spotted }\end{array}$ & $\begin{array}{l}\text { Grupo laranja- } \\
\text { acinzentado } 173 \mathrm{C} \\
\text { Grayed-orange group } 173 \mathrm{C}\end{array}$ & $\begin{array}{l}\text { Grupo laranja- } \\
\text { acinzentado } 174 \mathrm{~A} \\
\text { Grayed-orange group } 174 \mathrm{~A}\end{array}$ & $\begin{array}{l}\text { Grupo branco } 155 \mathrm{~B} \\
\text { White group } 155 \mathrm{~B}\end{array}$ & 2 & $\begin{array}{l}\text { Quadrada } \\
\text { Squared }\end{array}$ \\
\hline g168-99 & $\begin{array}{l}\text { Manchada e pintada } \\
\text { Spotted and dotted }\end{array}$ & $\begin{array}{l}\text { Grupo laranja- } \\
\text { acinzentado } 165 \mathrm{~B} \\
\text { Grayed-orange group } 165 \mathrm{~B}\end{array}$ & $\begin{array}{l}\text { Grupo laranja- } \\
\text { acinzentado } 175 \mathrm{~A} \\
\text { Grayed-orange group } 175 \mathrm{~A}\end{array}$ & $\begin{array}{l}\text { Grupo branco } 155 \mathrm{D} \\
\text { White group } 155 \mathrm{D}\end{array}$ & 1,5 & $\begin{array}{l}\text { Oval } \\
\text { Oval }\end{array}$ \\
\hline $\mathrm{g} 9 \mathrm{~m}-97$ & $\begin{array}{l}\text { Manchada } \\
\text { Spotted }\end{array}$ & $\begin{array}{l}\text { Grupo laranja- } \\
\text { acinzentado N167C } \\
\text { Grayed-orange group N167C }\end{array}$ & $\begin{array}{l}\text { Grupo laranja- } \\
\text { acinzentado } 166 \mathrm{~B} \\
\text { Grayed-orange group } 166 \mathrm{~B}\end{array}$ & $\begin{array}{l}\text { Grupo branco } 155 \mathrm{D} \\
\text { White group } 155 \mathrm{D}\end{array}$ & 2 & $\begin{array}{l}\text { Quadrada } \\
\text { Squared }\end{array}$ \\
\hline g119-99 & $\begin{array}{l}\text { Pintada } \\
\text { Dotted }\end{array}$ & $\begin{array}{l}\text { Grupo laranja- } \\
\text { esbranquiçado } 159 \mathrm{C} \\
\text { Orange-white group } 159 \text { C }\end{array}$ & $\begin{array}{l}\text { Grupo branco- } \\
\text { acinzentado } 156 \mathrm{C} \\
\text { Grayed-white group } 156 \mathrm{C}\end{array}$ & $\begin{array}{l}\text { Grupo amarelo-branco } 158 \mathrm{~A} \\
\text { Yellow-white group } 158 \mathrm{~A}\end{array}$ & 2,5 & $\begin{array}{l}\text { Redonda } \\
\text { Rounded }\end{array}$ \\
\hline $\mathrm{g} 1 \mathrm{~m}-95$ & $\begin{array}{l}\text { Manchada } \\
\text { Spotted }\end{array}$ & $\begin{array}{l}\text { Grupo laranja- } \\
\text { acinzentado } 166 \mathrm{~B} \\
\text { Grayed-orange group } 166 \mathrm{~B}\end{array}$ & $\begin{array}{l}\text { Grupo laranja- } \\
\text { acinzentado } 166 \mathrm{~A} \\
\text { Grayed-orange group } 166 \mathrm{~A}\end{array}$ & $\begin{array}{l}\text { Grupo amarelo-branco } 158 \mathrm{~A} \\
\text { Yellow-white group } 158 \mathrm{~A}\end{array}$ & 1,5 & $\begin{array}{l}\text { Redonda } \\
\text { Rounded }\end{array}$ \\
\hline g29m-94 & $\begin{array}{l}\text { Manchada } \\
\text { Spotted }\end{array}$ & $\begin{array}{l}\text { Grupo laranja- } \\
\text { acinzentado } 166 \mathrm{D} \\
\text { Grayed-orange group } 166 \mathrm{D}\end{array}$ & $\begin{array}{l}\text { Grupo laranja- } \\
\text { acinzentado } 166 \mathrm{~B} \\
\text { Grayed-orange group } 166 \mathrm{~B}\end{array}$ & $\begin{array}{l}\text { Grupo branco } 155 \mathrm{~B} \\
\text { White group } 155 \mathrm{~B}\end{array}$ & 2 & $\begin{array}{l}\text { Quadrada } \\
\text { Squared }\end{array}$ \\
\hline g59-95 & $\begin{array}{l}\text { Manchada } \\
\text { Spotted }\end{array}$ & $\begin{array}{l}\text { Grupo laranja- } \\
\text { acinzentado } 166 \mathrm{~A} \\
\text { Grayed-orange group } 166 \mathrm{~A}\end{array}$ & $\begin{array}{l}\text { Grupo laranja- } \\
\text { acinzentado } 166 \mathrm{D} \\
\text { Grayed-orange group } 166 \mathrm{D}\end{array}$ & $\begin{array}{l}\text { Grupo branco } 155 \mathrm{D} \\
\text { White group } 155 \mathrm{D}\end{array}$ & 1 & $\begin{array}{l}\text { Redonda } \\
\text { Rounded }\end{array}$ \\
\hline g 146-94 & $\begin{array}{l}\text { Manchada } \\
\text { Spotted }\end{array}$ & $\begin{array}{l}\text { Grupo amarelo- } \\
\text { esbranquiçado } 158 \mathrm{C} \\
\text { Yellow-white group } 158 \mathrm{C}\end{array}$ & $\begin{array}{l}\text { Grupo laranja- } \\
\text { acinzentado 156A } \\
\text { Grayed-white group } 156 \mathrm{~A}\end{array}$ & $\begin{array}{l}\text { Grupo branco } 155 \mathrm{~A} \\
\text { White group } 155 \mathrm{~A}\end{array}$ & 2 & $\begin{array}{l}\text { Quadrada } \\
\text { Squared }\end{array}$ \\
\hline g 10-94 & $\begin{array}{l}\text { Manchada } \\
\text { Spotted }\end{array}$ & $\begin{array}{l}\text { Grupo laranja- } \\
\text { acinzentado } 164 \mathrm{~A} \\
\text { Grayed-orange group } 164 \mathrm{~A}\end{array}$ & $\begin{array}{l}\text { Grupo laranja- } \\
\text { acinzentado } 166 \mathrm{~A} \\
\text { Grayed-orange group } 166 \mathrm{~A}\end{array}$ & $\begin{array}{l}\text { Grupo branco } 155 \\
\text { White group } 155 \mathrm{~A}\end{array}$ & 1,5 & $\begin{array}{l}\text { Quadrada } \\
\text { Squared }\end{array}$ \\
\hline g 123-99 & $\begin{array}{l}\text { Manchada e pintada } \\
\text { Spotted and dotted }\end{array}$ & $\begin{array}{l}\text { Grupo laranja- } \\
\text { acinzentado N167C } \\
\text { Grayed-orange group N167C }\end{array}$ & $\begin{array}{l}\text { Grupo laranja- } \\
\text { acinzentado } 166 \mathrm{~B} \\
\text { Grayed-orange group } 166 \mathrm{~B}\end{array}$ & $\begin{array}{l}\text { Grupo branco } 155 \mathrm{C} \\
\text { White group } 155 \mathrm{C}\end{array}$ & 2 & $\begin{array}{l}\text { Redonda } \\
\text { Rounded }\end{array}$ \\
\hline
\end{tabular}

cores do caule, das flores e das sementes, pois os manuais de cores são de difícil obtenção e pouco práticos para utilização no campo. Neste estudo, utilizou-se o manual de cores para uma classificação mais eficiente e internacionalmente aceitável, porém, mantiveram-se os outros critérios para que todas as linhagens inicialmente selecionadas por Godoy et al. $(1994,1997)$ possam ser uniformemente caracterizadas.

\section{Conclusões}

As 13 linhagens de Cajanus cajan descritas neste trabalho possuem características distintas e, em condições de campo, são facilmente identificáveis por suas características morfológicas.

A descrição de cores no caule, nas flores, nas sementes ou nas vagens de Cajanus cajan, com o auxílio do sistema de padrão de cores permitiu classificar as linhagens de forma internacionalmente aceitável.

\section{Literatura Citada}

COLOMBO, C.A. Estudo da variabilidade fenotípica do feijão guandu (Cajanus cajan (L.) Millsp.). Piracicaba: Escola Superior de Agricultura "Luiz de Queiroz", 1989. 131p. Dissertação (Mestrado em Zootecnia) - Escola Superior de Agricultura "Luiz de Queiroz", 1989.

GODOY, R.; BATISTA, L.A.R.; NEGREIROS, G.F. Avaliação agronômica e seleção de germoplasma de guandu forrageiro (Cajanus cajan (L.) Millsp.). Revista Brasileira de Zootecnia, v.23, n.5, p.742-49, 1994.

GODOY, R.; BATISTA, L.A.R.; NEGREIROS, G.F. Avaliação agronômica e seleção de germoplasma de guandu forrageiro (Cajanus cajan (L.) Millsp.) proveniente da Índia. Revista Brasileira de Zootecnia, v.26, n.3, p.447-453, 1997.

GODOY, R.; BATISTA, L.A.R.; SOUZA, F.H.D. et al. Caracterização de linhagens puras de guandu (Cajanus cajan (L.) Millsp.). Revista Brasileira de Zootecnia, v.32, n.3, p.546-555, 2003 
GODOY, R.; FUSHITA, A.T.; SOUZA, F.H.D. Caracterização de onze linhagens puras de guandu selecionadas em São Carlos, SP. Revista Brasileira de Zootecnia, v.33, n.6, p.2206-2213, 2004 (supl. 3).

INTERNATIONAL BOARD FOR PLANT GENETIC RESOURCES \& INTERNATIONAL CROP RESEARCH INSTITUTE FOR THE SEMI ARID TROPICS. Descriptors for pigeon-pea (Cajanus cajan (L.) Millsp.). Rome: IBPGR; Patancheru, India: ICRISAT, 1993. 31p.

THE ROYAL HORTICULTURAL SOCIETY. RHS colour chart. London: 2001. (4 fan).

WERNER, J.L. O potencial do guandu (Cajanus cajan(L.) Millsp.) como planta forrageira.Zootecnia, v.17, n.2, p.73-100, 1979.
WUTKE, E.B.; COSTA, J.D. Caracterização fenotípica e avaliação agronômica de genótipos de guandu (Cajanus cajan (L.) Millsp.). In: REUNIÃO DA SOCIEDADE BRASILEIRA PARA O PROGRESSO DA CIÊNCIA, 41., 1989, Fortaleza. Resumos... São Paulo: SBPC, 1989. v.41, p.12-12. 